\title{
EXPERIENCIAS ENTRE EL ARTE CONTEMPORÁNEO, LA CULTURA POPULAR Y EL INTERNET: DE EXPERIMENTOS CULTURALES A LA SELECTA - COOPERATIVA CULTURAL
}

\author{
Manuel Kingman G.
}

Fecha de recepción: 08/2016

Fecha de aceptación: 10/2016

\begin{abstract}
Resumen:
El presente ensayo trata sobre dos proyectos on line en Ecuador, toma como punto de partida el trabajo del colectivo Experimentos Culturales (2001 - 2009) y luego se concentra en las diversas prácticas llevadas a cabo por La Selecta - Cooperativa Cultural entre 2009 y 2013. Aborda el proceso que llevó a la consolidación del colectivo Experimentos Culturales, relacionando su emergencia con el contexto de crisis económica presente a principios de la década del 2000 y con una respuesta independiente y multidisciplinaria a esa crisis, que plantea construir plataformas de visibilización del pensamiento y el arte contemporáneo en un periodo de precariedad y falta de espacios para el arte. La segunda parte del artículo se concentra en algunas prácticas de la Selecta,- Cooperativa Cultural, este colectivo conformado por algunos de los miembros de Experimentos Culturales, continúa con algunas líneas de trabajo sin dejar de replantear sus prácticas.
\end{abstract}

Palabras claves: Arte contemporáneo en Ecuador, Proyectos on line Experimentos Culturales, La Selecta - Cooperativa cultural, Gestión Cultural.

\begin{abstract}
:
This paper discusses two online projects in Ecuador. The parting moment is the work of the art collective Experimentos Culturales (2001-2009), then describes different practices undertaken by La Selecta - Cooperativa Cultural between 2009 and 2013. This article approaches the process that controls the merging of Experimentos Culturales and relates its presence in the context of an economic crisis at the beginnings of 2000. This project is seen like a multidisciplinary response that suggests the use of independent platforms as a way of thinking contemporary art in a precarious period for art in Ecuador. After that, this paper sees some practices of La Selecta Cooperativa Cultural, this group followed by some members of Experimentos Culturales, persists in the work lines of the former group and rethinks its practices, as well.
\end{abstract}

Keywords: Contemporary ecuadorian art, On line projects, Experimentos Culturales, La Selecta Cooperativa cultural, Cultural managemen.

\section{Autor:}

Manuel Kingman (Quito, 1976). Máster en Antropología Visual FLACSO y Licenciado en Artes Plásticas PUCE. Docente de la Carrera de Artes Visuales de la PUCE. 


\section{Introducción}

¿Me pregunto cómo articular los sentidos de las prácticas individuales y si tiene sentido hacerlo? Algunas de mis prácticas están cercanas a lo que se entiende como práctica artística y han derivado en exposiciones, publicaciones, intervenciones artística, y otras, aunque no entran en esa categoría han estado relacionadas con el campo del arte, en el sentido de Bourdieu como un campo de fuerzas en las que distintos actores movilizan capitales específicos para conservarlo o transformarlo (1999, pp. 63-64).

Marcelo Expósito crítica la división y jerarquización de la producción cultural, entre ciertas actividades simbólicamente hegemónicas como la actividad artística y otras que son sustanciales en la dimensión comunicativa del arte contemporáneo, como escribir, organizar actividades, publicar, difundir pero que han sido relegadas por un sistema del arte que solo recoge parte final del proceso (2006).

En la sociedad contemporánea las funciones y roles de los productores culturales se complejizan. Para dar cuenta de la diversidad de actividades que emprenden los artistas contemporáneos, la investigadora colombiana Jimena Andrade Forero realizó una indagación interesante, ella interrogó a los artistas con la siguiente pregunta:

"cómo defines tu actuación?, intentando con esto indagar, en nuestro contexto, en dónde se considera que se sitúa el propio ejercicio, mediante cuáles palabras es definido, dónde se formaliza este, ¿en objetos? ¿En prácticas? ¿En elementos intermedios entre objeto y no objeto? (2011, p. 25)

Forero traslada esa pregunta a la revisión de la práctica del artista Marcel Broodthaers, para ubicar una ruptura que sobrepasa y diluye los límites del sistema del arte, los roles del artista y las ideas sobre su genialidad que derivan en la producción y exposición de objetos. Una práctica como la de Broodthaers (entre otros artistas conceptuales) es para Forero una práctica discursiva que abre las posibilidades del arte hacia posibilidades heterogéneas (Forero: 2011).

Quiero volver a mis prácticas, para enunciar la faceta de mi trabajo cultural que me interesa tratar. Definir la actuación propia se complejiza cuando como muchas personas de mi generación en el Ecuador, se ha emprendido una diversidad de actividades men mi caso aparte de las prácticas artísticas, he transitado por el ámbito de los trabajos ocasionales, la escritura, la docencia, la investigación, el cine documental, la gestión cultural y el diseño.

Lejos de componer una autobiografía, me interesa recoger una práctica específica, relacionada con proyectos on line. Debo decir que tengo la interrogante sobre la pertinencia de la escritura sobre mi propia práctica, pienso que uno siempre tendrá prejuicios, sobredimensionará algunos procesos y subestimará otros. Aunque en este ejercicio no hay objetividad posible, asumo el riesgo de hacerlo, pienso que aparte de recoger una parte de mi experiencia, recoge la de un colectivo de artistas y su respuesta frente al complejo panorama del campo del arte en la década del 2000.

He hablado de proyectos on line, ${ }^{1}$ para referirme a dos colectivos artísticos como son la Selecta- Cooperativa Cultural y Experimentos Culturales, cuya actividad ha sido diversa. Por un

1 Este término es utilizado por Marcelo Expósito para referirse a una serie de plataformas en la web como Republicart, Translate y Transform, estos proyectos tuvieron una dimensión colectivo y sirvieron como plataformas de posturas y textos críticos, especialmente dedicados a la crítica institucional (Expósito: 2008, p. 28) 
lado, estos proyectos han sido revistas online de arte contemporáneo y por otro han funcionado como plataformas de producción cultural.

Antes de intentar a hacer una reconstrucción de un periodo que va desde el 2001 hasta el 2013, quiero incorporar algunas entradas teóricas para definir, por un lado, las razones por las que se incurre en un trabajo laboralmente precario (Lorey, 2008) y por otro ubicar discusiones que sirvan para pensar en la utilidad de la noción de gestión cultural para abordar este tipo de prácticas. Hay que decir que muchas veces las decisiones, apuestas $y$ posturas que se toman en una trayectoria como productor cultural, no responden a una planificación estructurada. Lo cierto es que tampoco las múltiples actividades y procesos de trabajo responden a una autodefinición que coincida con la etiqueta asignada a ese rol.

Para entender la práctica que desarrollé y desarrollamos como colectivo es útil la noción de campo del arte (Bourdieu: 1994), aunque en ese entonces quizás creíamos que nuestro aporte al medio cultural era una práctica desinteresada y de servicio, en retrospectiva puedo decir que estábamos generando un proyecto que partía de nuestros intereses y que movilizaba un capital económico (nuestra fuerza de trabajo), para acumular un capital simbólico. El reconocerse como actores dentro de un campo del arte precario y poscrisis, también es de utilidad para pensar en la diversidad de actividades que emprendimos como colectivo y ubicarlas como una respuesta a la precariedad de la institución arte; en ese sentido, si el planteamiento de Bourdieu ubica a actores que tratan de transformar y conservar el campo del arte, nuestra práctica al igual que otros colectivos ecuatorianos de la época, como Tranvía Cero, Wash, Oído Salvaje,
Sujeto a Cambio, etc., ${ }^{2}$ trataba de construir unas condiciones para la producción artística contemporánea del Ecuador.

Cuando la fuerza de trabajo movilizada no genera ningún capital económico, sino solo capital simbólico, se puede hablar de una precarización del trabajo. Lorey (2008) trata sobre los complejos (y perversos) mecanismos presentes en el neoliberalismo, por medio de los cuales, a cambio de la promesa de libertad y autonomía del artista, se da una precarización del sí en el ámbito cultural, para la autora lo interesante del caso es que en el capitalismo cognitivo lejos de producirse una situación de sujeción y explotación directa del capital al individuo, se provoca una auto explotación, las personas forzadas a la precarización, afirman que, en tanto trabajadoras y trabajadores culturales, han elegido libremente unas condiciones precarias de vida y trabajo" (Lorey: 2008, p. 73).

El colectivo Tranvía Cero (2011) ubica a la gestión cultural como "una salida conflictiva y llena de tensiones" para la producción artística, según Tranvía Cero esa prácticas les ha posibilitado seguir produciendo en el campo del arte, y "les ha dado más réditos simbólicos más que económicos". Pienso que algo similar sucedió en nuestro caso, a partir de las conversaciones sostenidas con el artista Gonzalo Vargas (compañero en Experimentos Culturales y La Selecta), puedo decir que tenemos algo de aflicción de saber que aunque las actividades de

2 El proyecto Ecuador en Emergencia se lanzó en marzo de 2008 en el Bar Galería la Naranjilla Mecánica de Quito. El proyecto consistía en una compilación en DVD de plataformas artísticas colectivas, además de las ya nombradas anteriormente se incluían trabajos de: Sujeto a Cambio, ARTLAB Creación Contemporánea. Artes No Decorativas S. A, La Limpia, Full Dollar, El Bloque, Aequator_Lab Nucanchik People. Se puede encontrar información sobre este proyecto en http://lavanderiadearte. $\mathrm{com} / \mathrm{cms} /$ ? $p=388$. 
gestión nos posibilitaron emprender proyectos y relacionarnos con el campo del arte local e internacional, también nos distanciaron de nuestra práctica artística.

Quizás es necesario detenerse en comprender el concepto de gestión cultural para luego preguntarse si está acepción es eficaz para el medio local y para definir a estos proyectos. Hay que decir que mientras movilizábamos los proyectos, no nos auto definíamos sólo como gestores culturales o solo como artistas. Marcelo Expósito plantea que en el posfordismo se da una flexibilidad laboral y por lo tanto un desdibujamiento "del trabajo "clásico" del artista”, que provoca modelos difusos como los de artista-gestor. Bayardo ( ) ve necesaria la profesionalización de la gestión cultural, ya que es una práctica que aparte de suscitar proyectos, logra mediar entre los distintos agentes, se debate entre criterios de pensar al arte y a la cultura por su capacidad de atraer inversiones y promover rentabilidad económica y nociones de inclusión cultural y derechos culturales. Martinell, en un estudio sobre la emergencia de la noción de gestión cultural y su profesionalización en América Latina y España, aparte de evidenciar los procesos, discusiones y teorías que se suscitaron para la consolidación de esta noción, muestra a la gestión cultural

[...] como una nueva misión profesional más pro activa, y política, fruto de un análisis de la realidad cultural contemporánea. Las nuevas políticas no necesitaban de administradores clásicos que actúan dentro del sistema formal y burocrático, sino de líderes para emprender una nueva institucionalidad orientada mucho más hacia el proyecto y a la búsqueda de nuevos fines (Martinell: 2009, p. 282).
Indudablemente, en nuestros proyectos hubieran sido útiles conceptos, procedimientos y discusiones en torno a la Gestión Cultural, quizás nos hubieran posibilitado conseguir mayor financiamiento y proyectar objetivos claros a largo plazo. En la implementación de los proyectos, no habíamos incorporado esos conocimientos, por lo tanto, nuestra práctica se acerca mas a la noción de artista-gestor propuesta por Marcelo Expósito que a la de una práctica profesional en Gestión Cultural.

\section{Antecedentes: Experimentos Culturales, gestión, producción y difusión de las artes visuales en Quito. De 2001 a 2009.}

En el año 2000 y tras el feriado bancario de 1999, se dio una crisis económica que afectó a las instituciones del país. No fue diferente para las "instituciones del arte" que, debido a la fuerte remezón que sufrió el sistema económico nacional, se vieron seriamente afectadas. Se vino el cierre de las galerías a nivel nacional y con eso la caída del incipiente mercado del arte local. Mientras sucedía la crisis éramos estudiantes, fuimos testigos del cierre de las pocas galerías que todavía funcionaban, existía una institución arte que la percibíamos lejana, los horizontes para la vida profesional como artistas se redujeron ${ }^{3}$

3 En ese lapso se evidenció la falta de espacios de circulación para las prácticas artísticas. Creemos que en esos años se formó una "brecha referencial", aún existente hasta nuestros días, entre las diferentes generaciones de artistas en el país. Nos referimos a esta "brecha" como la carencia de conocimientos, por parte de las nuevas generaciones de artistas, de la historia reciente del arte contemporáneo ecuatoriano, y la falta de investigaciones sobre el tema, promovidas desde los espacios académicos o instituciones culturales. La falta de una investigación articulada y constante que alimente una historia del arte contemporáneo ha generado la inexistencia de contenidos a ser insertados en las cátedras de historia del arte de las universidades y centros educativos del país. Sin embargo, lo contradictorio del caso es que esa ausencia de contenidos no es sinónimo de carencia de producción 
Es en este contexto que surge Experimentos Culturales, en 20014. Éramos estudiantes de la Carrera de Artes Plásticas de la Pontificia Universidad Católica del Ecuador, que no contábamos con espacios de visibilización y circulación de nuestra producción artística y decidimos gestar una plataforma en línea en donde se pudiera dar cabida a la difusión, crítica y promoción de propuestas vinculadas, en un principio, a las artes visuales, y luego a la cultura popular.

En cuanto a la implementación de un espacio en la red, la idea resultó innovadora, ya que se estaba trabajando con una tecnología nueva para el medio local y relativamente reciente a nivel regional. Gracias a los bajos costos de mantenimiento y de producción de una plataforma web, era fácil mantener el espacio en contraposición a los costos que suponía un medio impreso; no obstante, durante los primeros ańos de vida del proyecto su progreso y visibilización fueron lentos a causa de la baja tasa de conectividad en el país.

Con el transcurso de los años el sitio se fue consolidando como una fuente importante de información sobre el arte contemporáneo del país, poniendo especial énfasis en la ciudad de Quito y llegando a tener un promedio de 90 mil visitantes al mes, importante suma para el medio local. El proyecto Experimentos Culturales llegó a albergar en línea a más de 80 propuestas de artes visuales que provenían de artistas, tanto emergentes como consolidados dentro del contexto local, y también albergó un

artística. En los noventa y durante la década siguiente se dieron interesantísimos procesos artísticos, generalmente aislados de los circuitos del arte contemporáneo global.

4 El colectivo estuvo conformado por Carla Estrella, Ana Lucía Garcés, Francisco Jiménez, Manuel Kingman y Gonzalo Vargas M. importante archivo con varias propuestas teóricas interdisciplinarias, entre las que se destacó, entre otras, la galería Full Dollar, proyecto del artista y antropólogo X. Andrade.

A partir de esta idea de interdisciplinariedad, el colectivo se conforma con integrantes provenientes de las artes visuales, la antropología, la comunicación y el diseño. Así surge un interés común por trabajar en temas de cultura popular en paralelo a los trabajos relacionados con las artes visuales contemporáneas. Mascarada fue un primer reflejo de este interés, que se articuló con una pequeña investigación en torno a las tradiciones populares quiteñas de fin de año. El colectivo se hizo de una colección de máscaras manufacturadas por distintos artesanos de la ciudad, y con las cuales se representan muchos de los tópicos más importantes del año que termina y se festeja en las celebraciones de esa época, entre ellos los políticos locales más odiados; personajes de la esfera política mundial, personajes de caricaturas o motivos que se vienen repitiendo desde comienzos de siglo como payasos, lobos y osos y animales. Tras la exposición de una galería online sobre estas máscaras logramos una primera e importante relación con el colectivo colombiano Popular de Lujo, que en ese entonces estaba comenzando a trabajar sobre la gráfica popular en Colombia.

Al transcurrir los años, tras el constante trabajo en línea y luego de articular redes de colaboración, logramos establecer varias relaciones locales y contactos con otros colectivos a nivel latinoamericano. Así llegamos a desarrollar importantes intercambios $y$ colaboraciones internacionales con Popular de Lujo, en Colombia, o con la ONG (Organización Nelson Garrido), de Venezuela. En el ámbito 
local se desarrollaron proyectos de colaboración como A la Carta, una serie de muestras de videoarte nacional e internacional que buscaban formar públicos y generar reflexión acerca del video arte. El proyecto se trabajó de manera conjunta con la curadora ecuatoriana María del Carmen Carrión y el espacio centro cultural El Pobre Diablo, y se llevó a cabo a lo largo de 4 años, incluyendo curadurías internacionales.

Entre otros proyectos también cabe nombrar a Primera y Segunda Vuelta (marzo y agosto de 2007), muestras de arte realizadas conjuntamente con la curadora ecuatoriana Ana Rodríguez. Este proyecto se centró en el desenvolvimiento de la política en el Ecuador desde el retorno a la democracia, y se basó en una convocatoria abierta a artistas locales que quisieron reflexionar sobre esta temática específica. Las propuestas participantes trataron a la política y al sistema vigente desde diversos temas de reflexión, entre ellos la memoria y los usos de la imagen y el poder.

Otro proyecto que cobró importancia a nivel local y que se basó en la estrecha relación de intereses que los miembros mantienen con la cultura popular, fue La Tienda. Con esta propuesta se buscó vincular la estética y las representaciones de varios productos comerciales de consumo popular a referencias artísticas y políticas para crear "productos comerciales híbridos" que resignificaban las nociones contenidas en el proceso. Así, los “jabones mágicos para artistas", los "enlatados de cultura", los "preservativos saborizados con platos típicos ecuatorianos", los "cereales del Che Guevara", entre otros, fueron las propuestas del colectivo y para las que se desarrolló una serie de comerciales para la TV, que ilustraban las bondades de cada uno de ellos.
Cabe resaltar que durante los ocho años que funcionó la plataforma de Experimentos Culturales, todo el trabajo fue desarrollado de manera autofinanciada por medio de la colecta anual que se realizaba entre los miembros del colectivo para solventar los gastos de dominio y hospedaje del sitio, y otros recursos varios de los demás que demandaban nuestras actividades. En ese entonces, la actualización de la página web era realizada con la lenta y pesada tecnología del html, y para cada puesta al día se diseñaba una galería distinta, lo cual requería un trabajo de varias horas.

Tras ocho años de gestión y luego de diferencias internas, el colectivo se separó, lo que supuso momentáneamente una crisis para el trabajo elaborado durante ese periodo. Afortunadamente, la crisis se superó rápidamente gracias a la voluntad de mantener a salvo el archivo creado durante tanto tiempo. Es así que algunos miembros de Experimentos Culturales pasaron a formar el colectivo La Selecta, y los archivos que eran parte de la plataforma anterior fueron trasladados al nuevo sitio y se determinaron nuevos objetivos para el proyecto que empezaba a gestarse.

Como conclusiones sobre esta importante primera parte de nuestro trabajo colectivo, cabe decir que, siendo estudiantes universitarios, nos involucramos en una tarea que nadie nos pidió hacer sino que se gestó en el encuentro de nuestros intereses y necesidades con un contexto desfavorable, y que todo aquel trabajo fue realizado con tenacidad, voluntad y deseos de construir bases para poder desarrollar nuestra práctica artística personal, misma que, no obstante, tuvo que quedar relegada mientras nos ocupamos de sacar adelante ese proyecto. 
Nuevas rutas: La Selecta - Cooperativa Cultural

La Selecta 5 , el nuevo proyecto emprendido por algunos de los miembros de Experimentos Culturales, coincidió con la popularización de los blogs y con un cambio tecnológico a través del cual se reemplazó el lento lenguaje del html por alimentadores de contenidos como wordpress, por medio de los cuales la alimentación de contenidos se vuelve más sencilla. En esta nueva etapa decidimos mantener el sitio web www.laselecta.org como un archivo que contiene parte del devenir del arte contemporáneo local, y alimentarlo esporádicamente, sin la regularidad de otros tiempos, para poder concentrarnos en nuestros proyectos personales y colectivos, mismos que ya se encuentran disponibles en el nuevo sitio.

Aunque como La Selecta hemos realizado proyectos colectivos de inserción en el espacio público, como la Intervención a Los Toros de Colores (2009), Sala de Espera (2009) y Proyecto Reservado (2009), y hemos realizado algunas investigaciones individuales, nuestro principal interés está relacionado con los espacios simbólicos y de consumo de las culturas populares. La cultura popular ha sido abordada por nuestra práctica a través del diseño gráfico y editorial, la fotografía, la investigación y el documental. En esa línea hemos realizado publicaciones web como Mamá Lucha en tu corazón (La Lucha libre) y Tributo al Rock.

Entre el 2011 y el 2013 desarrollamos un proyecto que tomó la forma de un libro de gran formato. Se trató de una investigación sobre los espacios de comida tradicional en

5 La Selecta estuvo conformada por Fernanda Andrade, Adrián Balseca, Manuel Kingman, Santiago Rosero y Gonzalo Vargas M.
Quito. Este proyecto nos planteó interrogantes éticas en torno al sentido de ingresar a estos espacios para luego representarlos con imágenes. Considerando que, particularmente en los medios masivos, es frecuente el desarrollo de una espectacularización de lo popular cercana a lo kitsch, asumimos nuestra investigación con una responsabilidad ética que contempla la contextualización histórica de los espacios y de los saberes de los informantes, mujeres y hombres que en algunos casos han mantenido de manera oral las tradiciones culinarias y, en otros, han inventado nuevos "secretos" de cocina.

En este proceso de investigación nos distanciamos de creer que nuestra actividad es salvadora de costumbres y tradiciones o que sirve de salvaguarda para nuestra identidad nacional, ya que tenemos muy claro que las costumbres y las identidades se transforman. Por el contrario, nos interesó captar la riqueza de la cultura popular, en su propio contexto y complejidad, con sus contaminaciones y contradicciones, y hacerlo buscando que nosotros, como fotógrafos e investigadores, y los dueños de los negocios quedemos satisfechos con la forma de representar los espacios y los saberes. Esta investigación también derivó en una exposición (29 de noviembre de 2012 a febrero del 2013 en el Centro de Arte Contemporáneo).

\section{Conclusión}

A partir de nuestra práctica nos preguntamos cómo se equilibran los intereses productivos y creativos con la gestión cultural, pensando que en nuestro caso se ha tratado de una gestión no profesional y llevada a cabo de manera no remunerada y que surgió como respuesta a una crisis institucional. Como ya 
señalamos, en la primera etapa de Experimentos Culturales predominó el trabajo de gestión, aunque también se desarrollaron actividades artísticas puntuales. En esta segunda etapa de La Selecta hay un predominio de la producción artística y la investigación en torno a la cultura popular, pero paralelamente seguimos manteniendo la plataforma web como una forma de archivo del arte contemporáneo en el Ecuador.

Entre arte contemporáneo y cultura popular en el Ecuador existen relaciones de apropiación y re significación patentes en las prácticas de muchos artistas contemporáneos. ${ }^{6}$ Creemos que estos dos ámbitos de nuestro interés constituyen un terreno amplio para la investigación y por eso los hemos abordado desde nuestra práctica individual y colectiva.

Para nuestra práctica ha sido importantísimo involucrarnos en procesos de investigación en torno a la cultura popular que nos han llevado a salir del ámbito muchas veces pequeño del arte contemporáneo y a relacionarnos con otras realidades. Nos ha obligado a tener un enfoque interdisciplinario y a pensar en la creación de un tipo de producción cultural que trascienda al pequeńo circuito consagrado del arte local y que logre tener una importante recepción social, considerando que estamos en un medio en que el arte contemporáneo es todavía invisible y que tiene un público limitado.

\section{Bibliografía:}

Andrade, J. (2011). "Prácticas discursivas", en Revista Puntos, No. 10. Departamento de Artes Visuales. Bogotá: Pontificia Universidad Javeriana.

Bourdieu, P. (1999) Razones Prácticas: sobre la teoría de la acción. Barcelona: Anagrama.

Ecuador en Emergencia. Recuperado de: http:// lavanderiadearte.com/cms/?p=388 el 20 de septiembre de 2016.

Expósito, M. (2006). "Entrar y salir de la institución: autovalorización y montaje en el arte contemporáneo". En Revista Transversal No 10.

Kingman, M. (2012). Arte contemporáneo y cultura popular: El caso de Quito. Quito: FLACSO Sede Ecuador.

Lorey, M. (2008). "Gubernamentalidad y precarización de sí. Sobre la normalización de los productores y las productoras culturales". En Producción cultural y prácticas instituyentes Lineas de ruptura en la critica institucional. Madrid: Traficantes de Sueños - Transform/

Martinell A. (2009). "Las interacciones en la profesionalización en gestión cultural". En García Canclini, Néstor; Martinell, Alfons. El poder de la diversidad cultural. Comunidad Iberoamericana.

6 Sobre esta correspondencia realicé una tesis de maestría que fue publicada por FLACSO. Arte Contemporáneo y cultura popular: El caso de Quito, 2012. 